\title{
Effect of Process Parameters on Purification of Aluminium Alloys by Backward Extrusion Process under a Semisolid Condition
}

\author{
Thet Thet Cho*, Sumio Sugiyama and Jun Yanagimoto \\ Institute of Industrial Science, The University of Tokyo, Tokyo 153-8505, Japan
}

Although the recycling of aluminium has many environmental and economic benefits, the accumulation of impurities is a problem in the case of repeated recycling. In this study, the purification of A7075 wrought aluminium alloy and ADC12 based hypereutectic aluminium alloy was conducted by the backward extrusion process under a semisolid condition. The effect of process parameters such as the semisolid temperature and backward extrusion ratio was investigated. From the results of optical microscopic imaging, scanning electron microscopy (SEM) and energy-dispersive X-Ray spectroscopy (EDS) analysis, it was confirmed that the percentage of purified aluminium, the distribution of aluminium and the yield of the purified part for A7075 alloy were significantly affected by the semisolid temperature and extrusion ratio. For ADC12 based hypereutectic aluminium alloy, it was found that the silicon flakes still remained even in the unextruded part after the purification process. [doi:10.2320/matertrans.M2015381]

(Received October 8, 2015; Accepted December 14, 2015; Published February 5, 2016)

Keywords: aluminium alloy, tramp element, backward extrusion, semisolid condition

\section{Introduction}

Aluminium is widely used owing to properties such as its light weight, high strength, corrosion resistance and good formability, and it is one of the most recyclable materials. Aluminium and its alloys can be recycled repeatedly without any loss in quality, and this can be considered as sustainable materials. The recycling of high quality aluminium scrap into new ingots requires 95\% less energy and greenhouse gas emission, than that necessary to produce primary aluminium from bauxite ore through the primary smelter route. ${ }^{1)}$ Thus, the recycling of aluminium saves raw materials, energy and reduces emissions and pressure on landfill sites. Although the recycling process has economic and environmental benefits, the increasing concentration of tramp elements is a major problem in the repeated recycling of materials.

In the conventional recycling process, primary aluminium is used to reduce the concentration of tramp elements in aluminium alloy scrap. In particular, wrought aluminium scrap cannot be used to produce new wrought alloy unless at least one of the tramp elements is diluted by the addition of primary aluminium. ${ }^{2}$ Moreover, underground reserves of bauxite ore, which is necessary to produce primary aluminium are expected to be depleted in the future. Thus, separation and reducing technologies that do not require primary aluminium for the purification of aluminium alloy scrap are necessary. Many of studies in the literature have suggested the use of physical separation technologies (premelt technologies), such as magnetic separation, air separation, eddy current separation, sink-float heavy media separation and color sorting, and chemical separation technologies (melt technologies) involving the addition of chemicals such as $\mathrm{NaCl}$ and fluxes. However, there have been few papers on the separation of tramp elements from metal alloy scrap by metallurgical separation technologies, in which the impurities are removed in accordance with the phase diagram.

The metallurgical separation technologies can be mainly divided into (1) the removal of tramp elements as intermetallic compounds, (2) zone refining processes, and

*Corresponding author, E-mail: thet-cho@iis.u-tokyo.ac.jp
(3) the removal of tramp elements by semisolid processing. ${ }^{3)}$ The first zone refining method was introduced by Pfann in 1952 for the purification of semiconductor materials, especially germanium. ${ }^{4}$ This method uses the solid-liquid phase transition to separate tramp elements by moving them from one end of bar to another. However, this method did not work for silicon and it has some limitations in the purification of metal alloys. Research on the purification of metal alloy scrap by semisolid processing (the rheorefining process) was started by Mehrabian et al. in 1974. ${ }^{5)}$ and further developed by Ichikawa et al. in $1997,{ }^{6}$ ) who suggested that pure aluminium could be removed from Al-Sn and Al-Ni binary alloys with high efficiency. In their process, aluminium alloy scrap was heated and maintained in the semisolid state to melt the grain boundaries. When the impurities that accumulated at the grain boundaries were liquefied, they were separated using steel or aluminium porous filters. Although a significant amount of the liquid phase containing the impurities could be separated, it took a long time to filter the impurities.

Recently, Sugiyama et al. proposed a new method for the purification of aluminium alloy scrap that involved backward extrusion under a semisolid condition. ${ }^{7}$ In this method, liquid metal is gradually solidified from the container wall to the central portion of the container. After achieving the semisolid state, the liquid phase containing the tramp elements is extracted by backward extrusion. This method is very fast and simple. In our previous paper, we reported the purification mechanism of backward extrusion process under the semisolid condition, in which the liquid phase containing the tramp elements accumulates at the grain boundaries while the number of grain boundaries increases and small grains are formed in the extruded part as a result of backward extrusion. ${ }^{8)}$ Also, the purified aluminium was enriched in the unextruded part. It was found that the concentrations of $\mathrm{Zn}$ and $\mathrm{Cu}$ were reduced and that the most undesirable elements Fe and Si could be effectively separated in A7075 alloy and A7N01 alloy. Moreover, it was found that repeated backward extrusion caused an increase in the weight percentage of purified aluminium in the unextruded part.

In this study, the backward extrusion process was investigated to determine the effect of semisolid process 
Table 1 Chemical composition (mass \%).

\begin{tabular}{lcccccccccc}
\hline \multicolumn{1}{c}{ Materials } & $\mathrm{Si}$ & $\mathrm{Fe}$ & $\mathrm{Cu}$ & $\mathrm{Mn}$ & $\mathrm{Mg}$ & $\mathrm{Zn}$ & $\mathrm{Cr}$ & $\mathrm{Ni}$ & $\mathrm{Sn}$ & $\mathrm{Al}$ \\
\hline A7075 & 0.4 & 0.5 & 2.0 & 0.3 & 2.4 & 6.1 & 0.28 & - & - & 88.02 \\
\hline $\begin{array}{l}\text { ADC12 based } \\
\text { hypereutectic }\end{array}$ & 16 & 0.53 & 1.71 & 0.16 & 0.24 & 0.57 & - & 0.06 & 0.04 & 80.7 \\
\hline
\end{tabular}

Table 2 Experimental conditions.

\begin{tabular}{ll}
\hline Materials & $\begin{array}{l}\text { A7075 (wrought aluminium alloy) } \\
\text { ADC12 based hypereutectic aluminium alloy }\end{array}$ \\
\hline Semisolid temperature & $475-640$ (A7075) \\
range $\left({ }^{\circ} \mathrm{C}\right)$ & $530-570$ (ADC12 based hypereutectic Al alloy) \\
\hline Backward Extrusion & \\
Billet diameter $(\mathrm{mm})$ & $\varnothing 32$ \\
Billet height (mm) & 40 \\
Container diameter (mm) & $\varnothing 32$ \\
Container height (mm) & 60 \\
Extrusion temperature & $610,615,620,625$ (A7075) \\
$\left({ }^{\circ} \mathrm{C}\right)$ & $550(\mathrm{ADC} 12$ based hypereutectic aluminium \\
& alloy) \\
Extrusion ratio & $2.5,7,10$ \\
Load (kN) & $3.0-3.8$ \\
\hline
\end{tabular}

conditions such as the semisolid temperature and extrusion ratio on the purification of A7075 wrought aluminium alloy, which is widely used in the aerospace industry, and ADC12 based hypereutectic aluminium alloy, which is used in the automotive industry.

\section{Experimental Procedure and Conditions}

A7075 wrought aluminium alloy with zinc as the primary alloying element and ADC12 based hypereutectic aluminium alloy with silicon as main alloying element were selected as the starting materials representing the aluminium scrap in this study. The semisolid temperature range of A7075 wrought aluminium alloy and that of $\mathrm{ADC} 12$ based hypereutectic aluminium alloy were measured by obtaining the cooling curve using a DL708E digital recorder. The chemical compositions of the starting materials are shown in Table 1 and the experimental conditions are shown in Table 2. The billet size was $\varnothing 32 \mathrm{~mm}$ with a $40 \mathrm{~mm}$ height. The experiments were conducted at semisolid temperatures of $610^{\circ} \mathrm{C}, 615^{\circ} \mathrm{C}$, $620^{\circ} \mathrm{C}$ and $625^{\circ} \mathrm{C}$ to determine the effect of the semisolid temperature on the distribution and concentration of aluminium in the unextruded part after the purification of A7075 alloy. Moreover, extrusion ratios of 2.5, 7 and 10 were used to investigate the effect of the extrusion ratio. For ADC12 based hypereutectic aluminium alloy, the experiments were conducted at $550^{\circ} \mathrm{C}$ with extrusion ratios of $2.5,7$ and 10 . The backward extrusion process for the purification of the alloys was carried out using a laboratory scale manual press. The average extrusion velocity was $10 \mathrm{~mm} / \mathrm{s}$. The material was placed in a cylindrical steel container and melted by heating to $700^{\circ} \mathrm{C}$. The liquid material was then gradually solidified in air to achieve the semisolid condition. When suitable semisolid slurry was obtained at the desired semisolid temperature,
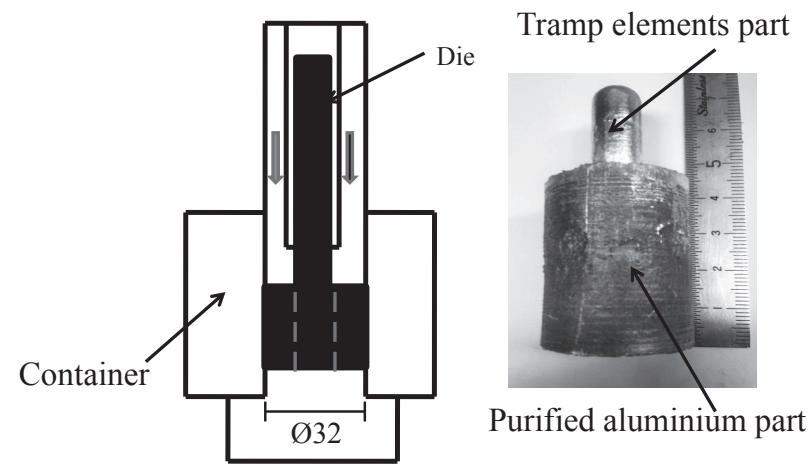

Fig. 1 Outline of backward extrusion method and extruded sample.

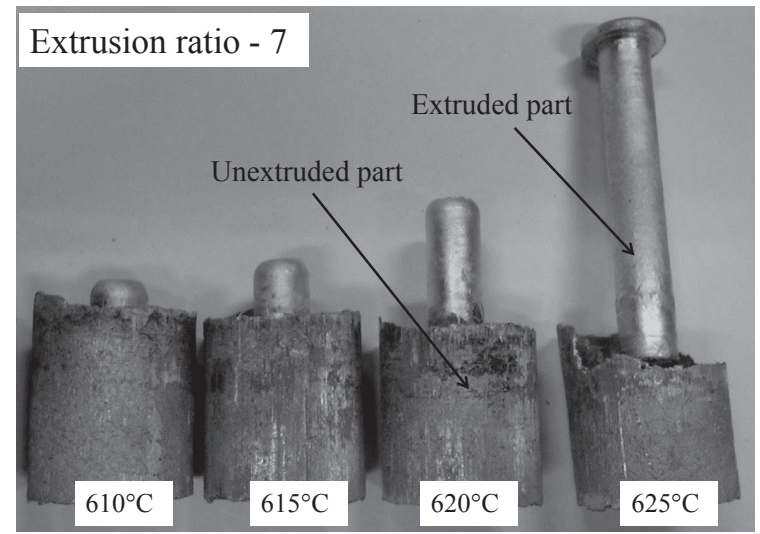

Fig. 2 Extruded specimens of A7075 alloy at semisolid temperatures of $610^{\circ} \mathrm{C}, 615^{\circ} \mathrm{C}, 620^{\circ} \mathrm{C}$ and $625^{\circ} \mathrm{C}$.

backward extrusion was conducted and finally the extruded sample was cooled in air. An outline of the backward extrusion process and the extruded sample are shown in Fig. 1. Each extruded specimen was cut along the axial direction then polished by 500,1000, 1500 and 2400 grit abrasive paper, which was followed by buffer polishing and etching. After polishing and etching the unextruded part containing the purified aluminium and the extruded part containing the tramp elements, the microstructures were observed using an optical microscope. The specimens were analyzed by SEM and EDS analysis was conducted to evaluate the distribution of chemical elements in the specimen after backward extrusion under semisolid condition.

\section{Results}

\subsection{Results for the purification of $\mathbf{A 7 0 7 5}$ alloy at different semisolid temperatures}

The semisolid temperature range of A7075 alloy is 475$640^{\circ} \mathrm{C}$ as shown in Table 2. To determine the effect of the semisolid temperature on the purification of A7075 alloy, the extruded samples were formed at semisolid temperatures of $610^{\circ} \mathrm{C}, 615^{\circ} \mathrm{C}, 620^{\circ} \mathrm{C}$ and $625^{\circ} \mathrm{C}$ with an extrusion ratio of 7. Figure 2 shows the specimens extruded at these semisolid temperatures, and Fig. 3 shows the optical microstructures of the unextruded parts of the extruded specimens, which contained purified aluminium. According to the results of optical microscopy, the liquid phase did not exist in all of the unextruded parts of the A7075 alloy. Figure 4 shows the results of mapping the aluminium distribution in the grains of 


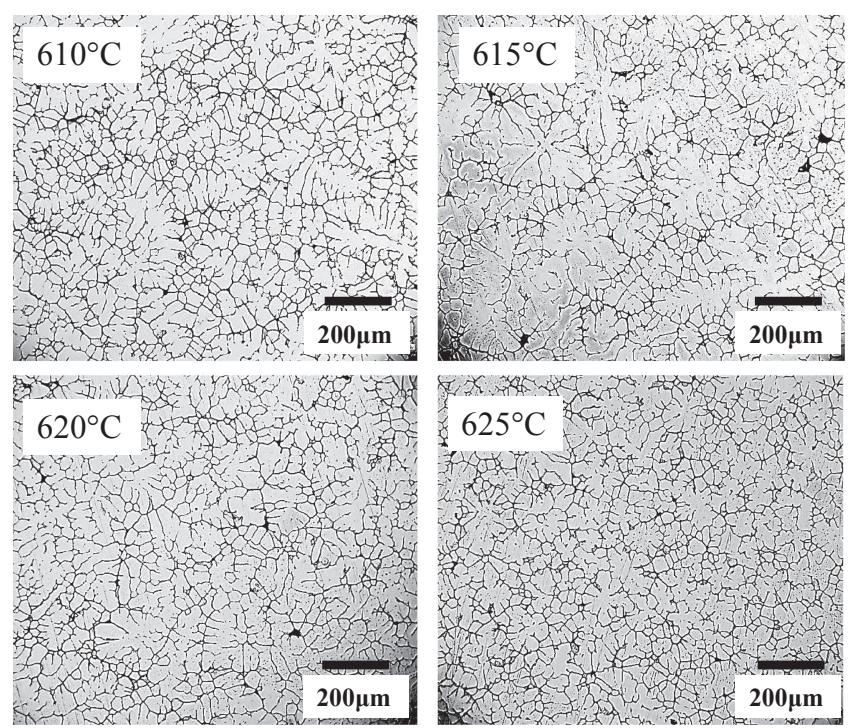

Fig. 3 Optical microstructures of the unextruded parts of $\mathrm{A} 7075$ alloy at semisolid temperatures of $610^{\circ} \mathrm{C}, 615^{\circ} \mathrm{C}, 620^{\circ} \mathrm{C}$ and $625^{\circ} \mathrm{C}$.

the unextruded parts formed at semisolid temperatures of $610^{\circ} \mathrm{C}, 615^{\circ} \mathrm{C}, 620^{\circ} \mathrm{C}$ and $625^{\circ} \mathrm{C}$ obtained by EDS.

It was found that the purified aluminium grains were only distributed homogeneously in the unextruded part formed at $620^{\circ} \mathrm{C}$, while the remaining tramp elements condensed at the boundaries of the aluminium grains. To know the weight percentage of purified aluminium in the unextruded part, the ten different grains were selected and ten points in the central area of each grain were analyzed by EDS. Figure 5 shows a comparison of the average weight percentage of purified aluminium in the unextruded parts after backward extrusion obtained by EDS. The variation of the error bar was narrow only in the sample which was made at $620^{\circ} \mathrm{C}$ and it means that the aluminium was distributed homogeneously. It was confirmed that the percentage of purified aluminium was increased from $88 \%$ before purification to $94 \%$ after purification and that a larger amount of tramp elements agglutinated at the grain boundaries between aluminium grains at the optimum semisolid temperature of $620^{\circ} \mathrm{C}$.

\subsection{Results for the purification of A7075 alloy with different extrusion ratios}

As mentioned above, it was found that the semisolid temperature of $620^{\circ} \mathrm{C}$ was most effective for the purification of A7075 alloy. To investigate the effect of the extrusion ratio on the purification of A7075 alloy, samples were extruded at $620^{\circ} \mathrm{C}$ with extrusion ratios of $2.5,7$ and 10 . Figure 6 shows the optical microstructures of the unextruded parts of the samples formed at $620^{\circ} \mathrm{C}$ with the above extrusion ratios. It was found that the liquid phase still remained even in the unextruded part that was formed at $620^{\circ} \mathrm{C}$ with an extrusion ratio of 10 . This means that an extrusion die hole with a small diameter, which corresponds to a high extrusion ratio, is unsatisfactory for the purification of metal alloy scrap. Figure 7 shows the results of EDS mapping analysis of the unextruded parts formed at $620^{\circ} \mathrm{C}$ with extrusion ratios of 2.5 , 7 and 10. According to the results of mapping analysis, the distribution of purified aluminium was not homogeneous and the aluminium concentration was lower near the grain boundaries in the unextruded part formed with the extrusion ratio of 10 . However, the purified aluminium was more homogeneously distributed in the grains in the unextruded parts of the samples formed with extrusion ratios of 2.5 and 7.

To know the weight percentage of purified aluminium in the unextruded part, the ten different grains were selected and ten points in the central area of each grain were analyzed by EDS. Figure 8 shows a comparison of the weight percentage of aluminium in the unextruded parts of the samples formed with extrusion ratios of 2.5, 7 and 10 obtained by EDS. It was found that the percentage of aluminium was $94.2 \%$ in the unextruded parts of the samples formed with extrusion ratios of both 2.5 and 7 , compared with $88 \%$ for the sample before backward extrusion. Although the weight percentage of purified aluminium was almost the same in the unextruded parts formed with extrusion ratios of 2.5 and 7, a higher yield of the purified aluminium part was achieved at the extrusion ratio of 7 . Figure 9 shows the effect of the extrusion ratio on the yield of the purified part. The above results confirmed that the semisolid temperature and extrusion ratio affected the homogeneity of the distribution of purified aluminium in the unextruded part and the yield of the purified part.

\subsection{Results for the purification of ADC12 based hyper- eutectic aluminium alloy}

ADC12 based hypereutectic aluminium alloy contains silicon ( $\mathrm{Si}$ ) as the main alloying element. The semisolid temperature range of $\mathrm{ADC} 12$ based hypereutectic aluminium alloy is $530-570^{\circ} \mathrm{C}$. Before conducting the backward extrusion process at a semisolid temperature, the chemical composition of the ADC12 based hypereutectic aluminium alloy was analysed by EDS. It was found that the silicon content in the ADC12 based hypereutectic aluminium alloy was about $16 \%$, identical to that in Table 2. Actually, this value is higher than that for the standard composition of ADC12 aluminium die casting alloy. Backward extrusion was conducted at the semisolid temperature of $550^{\circ} \mathrm{C}$ with an extrusion ratio of 7 , which was the optimum extrusion ratio for A7075 in the previous section.

Figure 10 shows optical microscopic images of the unextruded part, which contained purified aluminium, and the extruded part, which contained condensed tramp elements, of the ADC12 based hypereutectic aluminium alloy. It is clear that very fine grain and the liquid phase accumulated in the extruded part, whereas the liquid phase containing the tramp elements still remained in the unextruded part. To determine the effect of the extrusion ratio on the purification of $\mathrm{ADC} 12$ based hypereutectic aluminium alloy, backward extrusion was conducted again with extrusion ratios of 2.5 and 10 . Figure 11 shows the optical microstructures of the unextruded parts of ADC12 based hypereutectic aluminium alloy with extrusion ratios of 2.5, 7 and 10. Silicon flakes still remained in all of the unextruded parts. Figure 12 shows the results of EDS mapping analysis of the unextruded parts of ADC12 based hypereutectic aluminium alloy at $550^{\circ} \mathrm{C}$ with extrusion ratios of 2.5, 7 and 10. It was clarified that $\mathrm{Si}$, the main tramp element in ADC12 based hypereutectic aluminium alloy, could not be removed from the samples, regardless of the extrusion ratio. The weight percentage of Silicon in the 

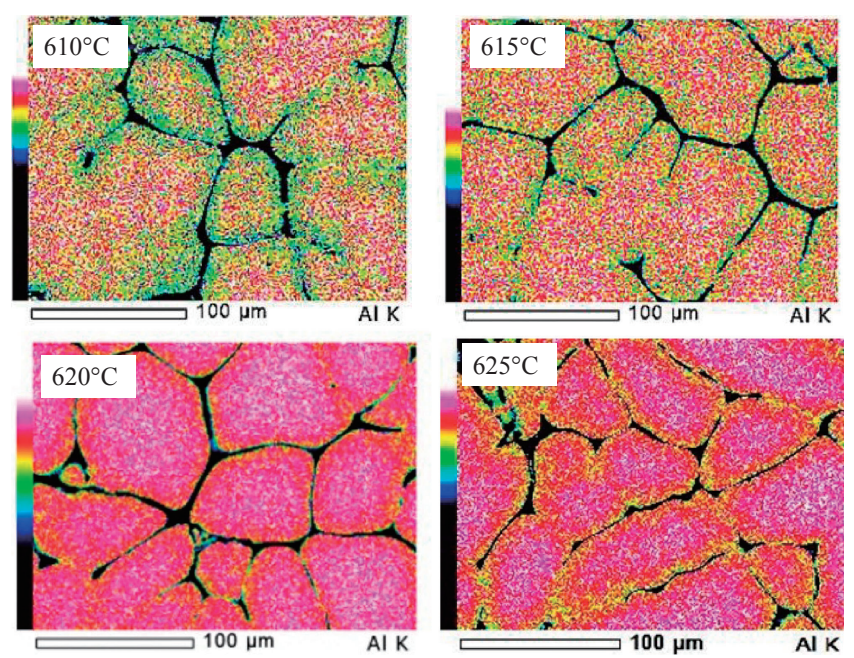

Fig. 4 EDS mapping analysis of aluminium in the unextruded part of A7075 at semisolid temperatures of $610^{\circ} \mathrm{C}, 615^{\circ} \mathrm{C}, 620^{\circ} \mathrm{C}$ and $625^{\circ} \mathrm{C}$.

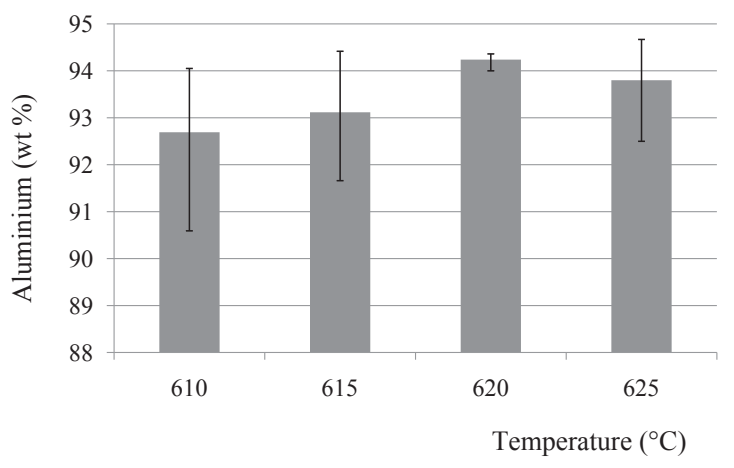

Fig. 5 Comparison the weight percentage of aluminium in the unextruded parts of A7075 at semisolid temperatures of $610^{\circ} \mathrm{C}, 615^{\circ} \mathrm{C}, 620^{\circ} \mathrm{C}$ and $625^{\circ} \mathrm{C}$.
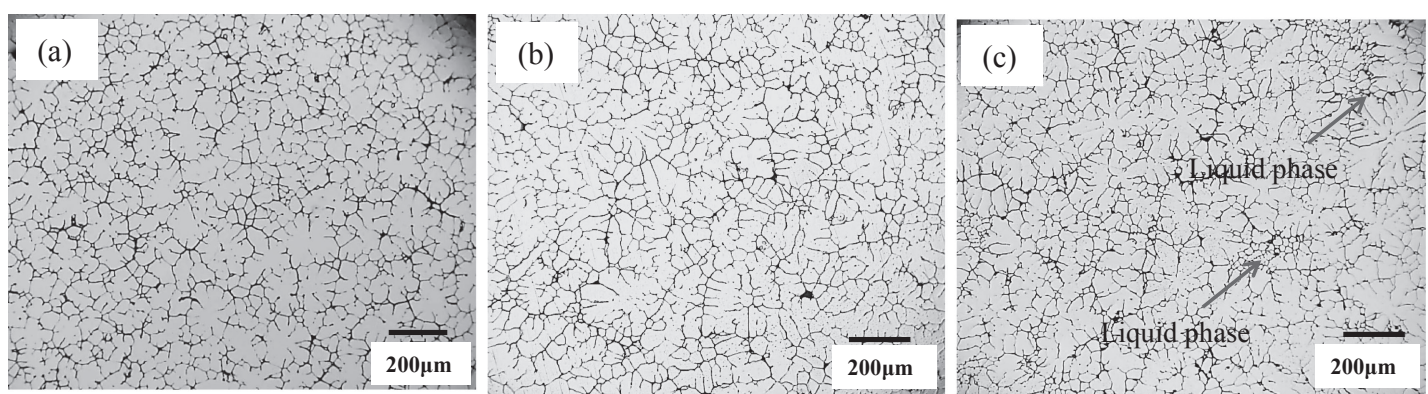

Fig. 6 Optical microstructures of unextruded parts of A7075 alloy at semisolid temperature of $620^{\circ} \mathrm{C}$ with extrusion ratios of (a) 2.5 , (b) 7 and (c) 10 .
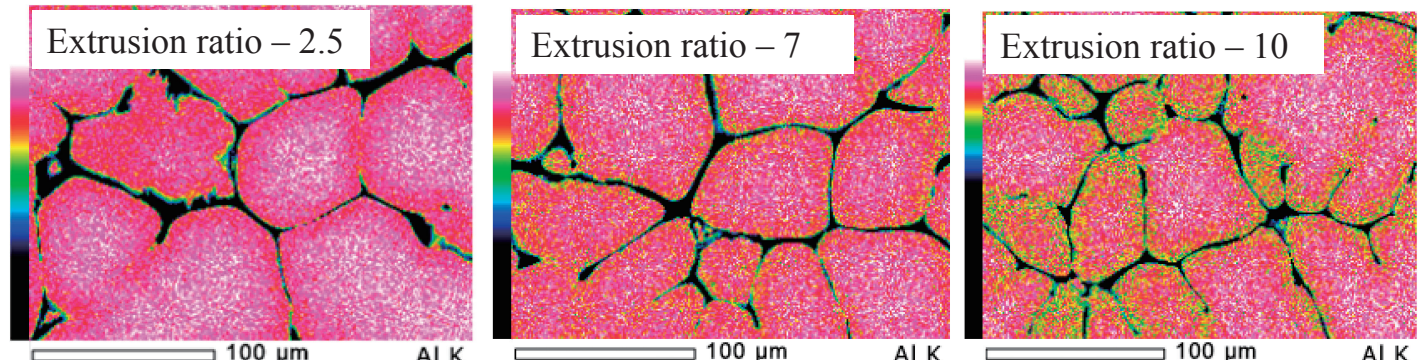

Fig. 7 EDS mapping analysis of aluminium in the unextruded parts of A7075 alloy at $620^{\circ} \mathrm{C}$ with extrusion ratios of 2.5 , 7 and 10 .

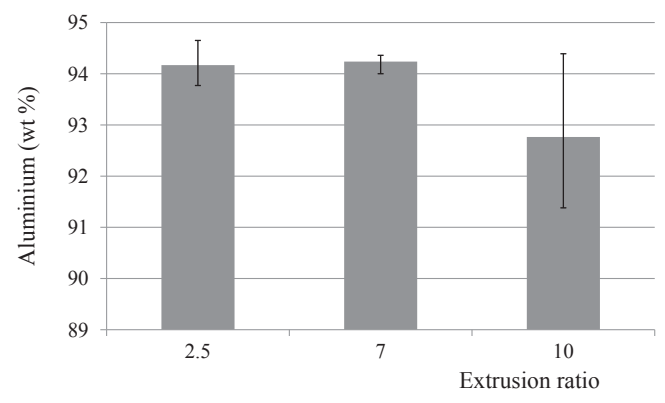

Fig. 8 Comparison the weight percentage of aluminium in the unextruded parts of A7075 alloy at $620^{\circ} \mathrm{C}$ with extrusion ratios of $2.5,7$ and 10 .

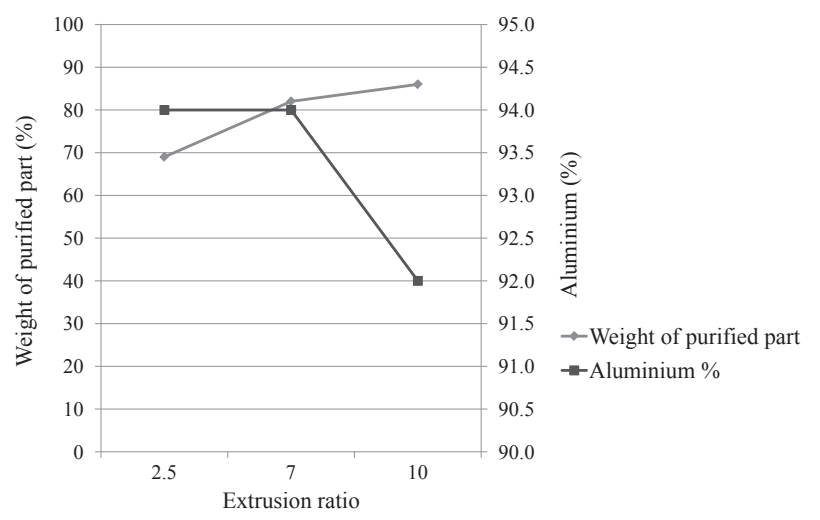

Fig. 9 Effect of the backward extrusion ratio on the yield of the purified part. 


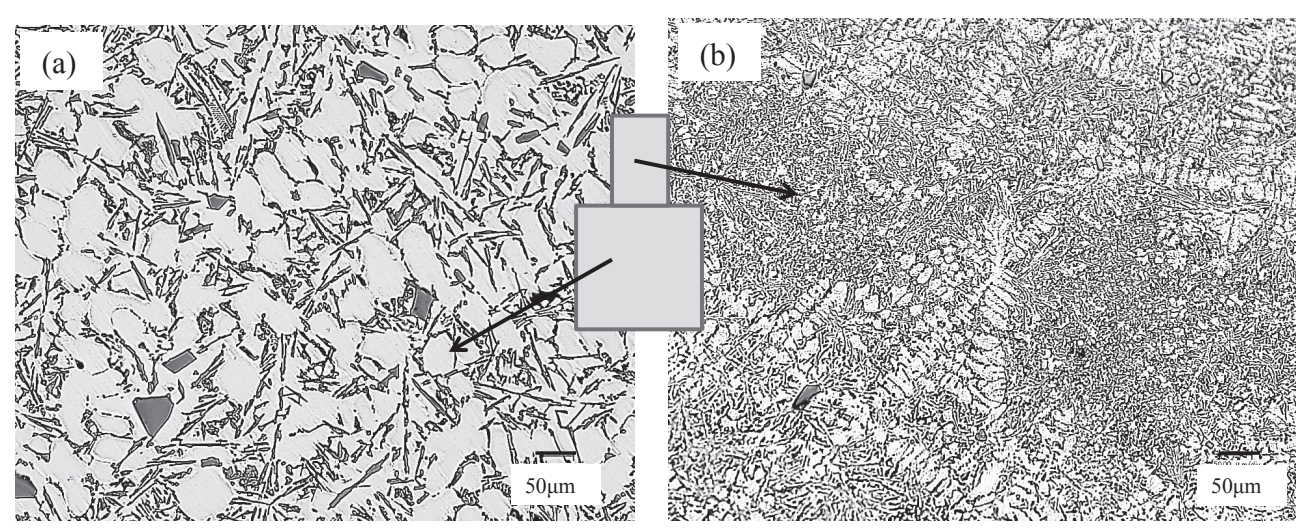

Fig. 10 Optical microstructures of (a) unextruded part and (b) extruded part of ADC12 based hypereutectic aluminium alloy.
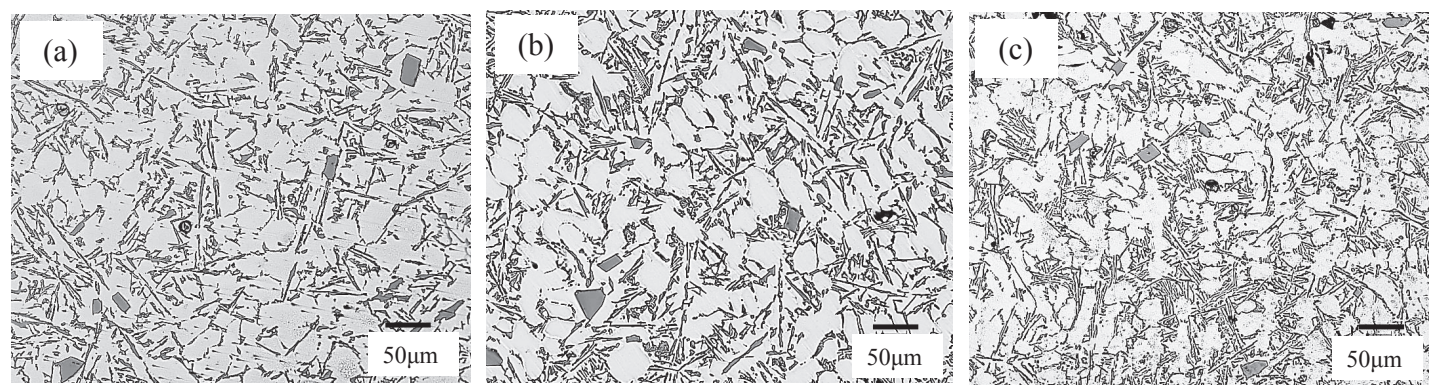

Fig. 11 Optical microstructures of the unextruded parts of $\mathrm{ADC} 12$ based hypereutectic aluminium alloy at $550^{\circ} \mathrm{C}$ with extrusion ratios of (a) 2.5, (b) 7 and (c) 10 .
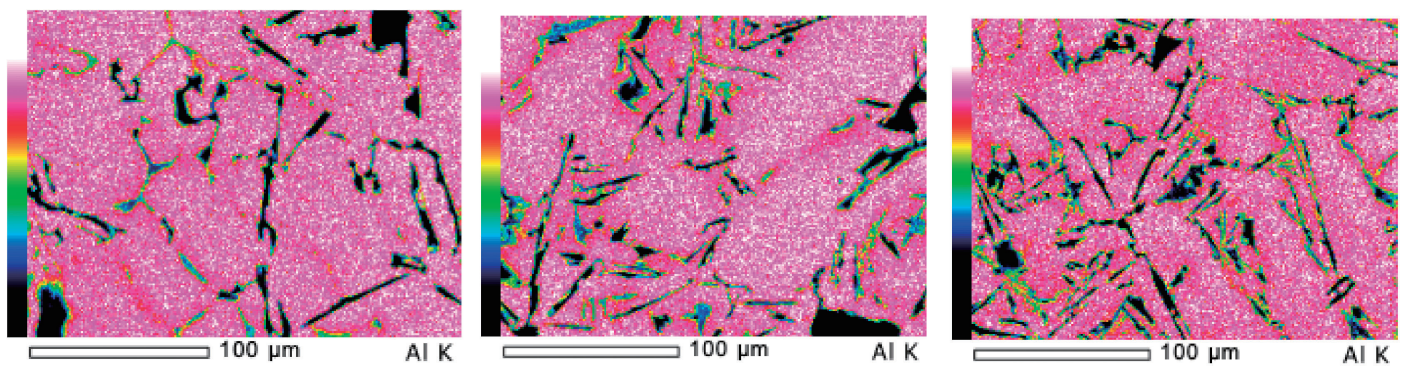

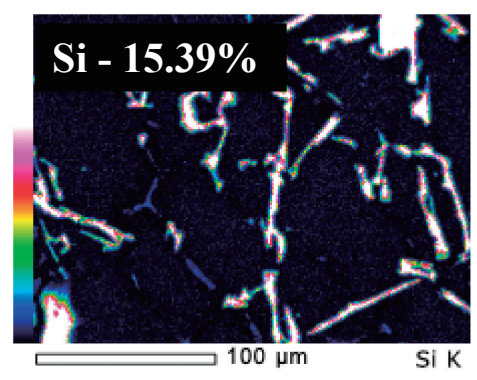

(a)

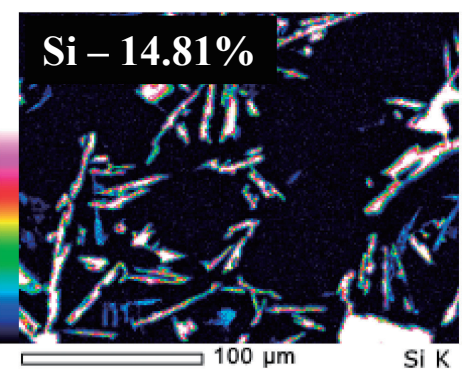

(b)

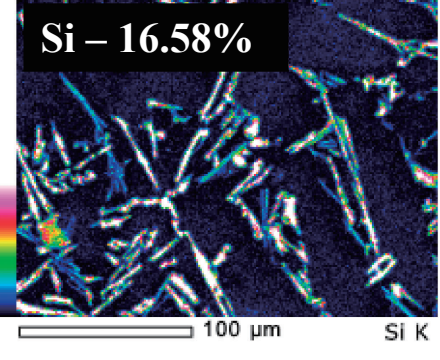

(c)

Fig. 12 EDS mapping analysis of the unextruded parts of $\mathrm{ADC} 12$ based hypereutectic aluminium alloy at $550^{\circ} \mathrm{C}$ with extrusion ratios of (a) 2.5 , (b) 7 and (c) 10 .

unextruded part could not be reduced significantly and almost the same as the sample before backward extrusion even the experiments were conducted with different extrusion ratio.

\section{Discussions}

\subsection{Effect of process conditions on purification of A7075 wrought aluminium alloy}

As mentioned in a previous section, the distribution of aluminium and the weight percentage in the unextruded parts of the A7075 samples were affected by the extrusion temperature under the semisolid condition. When the backward extrusion was conducted at $625^{\circ} \mathrm{C}$, which is near the liquidus temperature, the liquid phase containing the tramp elements was trapped near the grain boundaries in the unextruded part after backward extrusion, as shown in Fig. 4, and the weight percentage of purified aluminium in the unextruded part increased as shown in Fig. 5. Moreover, when the backward extrusion was conducted at the low temperatures of $610^{\circ} \mathrm{C}$ and $615^{\circ} \mathrm{C}$, the tramp elements could 


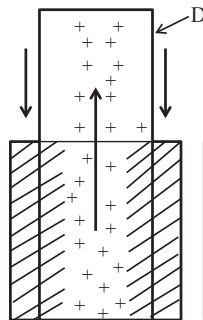

(a)

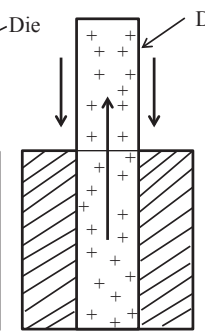

(b)

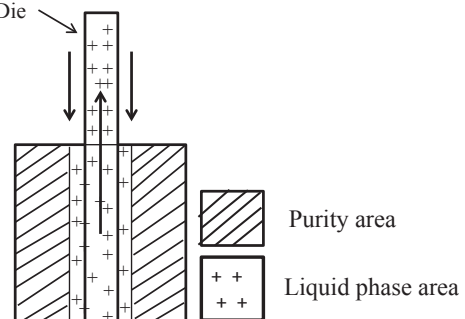

(c)
Fig. 13 Schematic diagram of the liquid extraction phenomena for the extrusion ratios of (a) 2.5 (b) 7 and (c) 10 .

not be squeezed out of the Al-rich grains in the unextruded parts and weight percentage of purified aluminium was low. The results of this study are in agreement with those of a previous study on solidification, in which it was reported that if the solidification speed is too high, the purification process is ineffective and a solid mass is obtained with a composition close to that of the molten scrap, and if the solidification speed is too low, the tramp elements may become incorporated in the solidified mass and reduce its purity. $\left.{ }^{9}\right)$ In the purification of A7075 alloy, the suitable backward extrusion temperature within the semisolid temperature range is limited. A semisolid temperature of $620^{\circ} \mathrm{C}$ is most suitable for the purification of A7075 wrought aluminium alloy.

In addition, when the backward extrusion was conducted at $620^{\circ} \mathrm{C}$ with an extrusion ratio of 10 , the purified aluminium was not distributed homogeneously in the unextruded part. The tramp elements still remained in the unextruded part and could not be fully removed owing to the small diameter of the extrusion die hole, which resulted in higher flowing resistance of the liquid phase enriched with the tramp elements. An extrusion ratio of higher than 10 was not considered in this study. When the backward extrusion was conducted with a low extrusion ratio of 2.5 , the purified aluminium passed through the unextruded part owing to the large diameter of the extrusion die hole, and the yield of the purified part decreased. However, aluminium was distributed homogeneously in the grains of the unextruded part and the weight percentage of aluminium was almost the same as that for the sample formed with an extrusion ratio of 7 as shown in Fig. 8. The weight of the unextruded parts can be varied by the difference in extrusion ratio as shown in Fig. 9. It was confirmed that the yield of the purified part was varying according to the different extrusion ratio. Figure 13 shows a schematic diagram of the liquid extraction phenomena for different extrusion ratios.

\subsection{Effect of process conditions on purification of ADC12 based hypereutectic aluminium alloy}

The silicon content in the ADC12 based hypereutectic aluminium alloy before backward extrusion was about $16 \%$ as shown in Table 1. Although the backward extrusion process was carried out at $550^{\circ} \mathrm{C}$ with different extrusion ratios, silicon could not be removed from the unextruded parts of the samples. As mentioned before, ADC12 based hypereutectic aluminium alloy contains silicon, which is the main alloying element. According to the Al-Si phase diagram, the weight percentage of silicon at the eutectic point is $12 \%$. Since the silicon content in the ADC12 based hypereutectic aluminium alloy before purification exceeded this value, the hypereutectic tramp element could not be removed regardless of the extrusion ratio. The difficulty of removing the tramp element silicon from the ADC12 based hypereutectic aluminium alloy which was used in this study agreed with the work of Boender et al., who reported that when a hypoeutectic mixture crystallises, the impurities are concentrated in the liquid phase and the purity of the crystals increases. ${ }^{10)}$ Thus, it was confirmed that the purification of the ADC12 based hypereutectic aluminium alloy was poor due to the hypereutectic tramp element of silicon. The purification of aluminium by backward extrusion at a semisolid temperature is only suitable for hypoeutectic mixture alloys.

\section{Conclusion}

Backward extrusion for the purification of A7075 wrought aluminium alloy and ADC12 based hypereutectic aluminium alloy was conducted at semisolid temperatures to investigate the effect of process parameters. The percentage of aluminium was increased from $88 \%$ before purification to $94 \%$ in the unextruded part of A7075 and the aluminium was homogeneously distributed when backward extrusion was carried out at $620^{\circ} \mathrm{C}$ with extrusion ratios of 7 and 2.5 , although the lower extrusion ratio reduced the yield of the purified part. It was clarified that the specific semisolid temperature and extrusion ratio are important factors in the purification of aluminium alloys. In the ADC12 based hypereutectic aluminium alloy, the distribution of aluminium was not homogeneous after backward extrusion and Si flakes still remained in the unextruded parts of all samples. Thus, it was confirmed that the amount of the tramp elements could be reduced under their concentration on eutectic point.

\section{Acknowledgements}

This study was financially supported by a Grant-in Aid for Scientific Research on the Innovation Area, "Bulk Nanostructured Metals" through MEXT, Japan. And, it was supported by Mitsubishi Research Institute of Asia Research Fellow Scholarship.

\section{REFERENCES}

1) S. K. Das: Mater. Sci. Forum 519-521 (2006) 1239-1244.

2) V. Kevorkijan: J. Metall. 16 (2010) 103-114.

3) G. Gaustad, E. Olivetti and R. Kirchain: J. Resou. Conserv. Recycl. 58 (2012) 79-87.

4) W. G. Pfann: Trans. AIME 194 (1952) 747.

5) R. Mehrabian, D. R. Geiger and M. C. Flemings: Met. Trans. 5 (1974) $785-787$.

6) K. Ichikawa, M. Katoh, F. Asuke and Y. Nakazawa: Mater. Trans., JIM 38 (1997) 622-629.

7) S. Sugiyama, Y. Meng and J. Yanagimoto: Solid State Phenom. 192193 (2012) 494-499.

8) T. T. Cho, Y. Meng, S. Sugiyama and J. Yanagimoto: Int. J. Precision Eng. Manufact. IJPEM 16 (2015) 177-183.

9) J. F. Verdier, J. R. Butruille, M. Leroy and D. Valax: Process for Recycling Aluminium Alloy Scrap coming from the Aeronautical Industry, Patent No. 20090285716, (2009).

10) W. Boender, C. J. Waringa, G. P. Krielaart, A. Folkertsma and D. Verdoes: Miner. Metals Mater. Soc. 1 (2002) 879-884. 